\title{
Estrogen receptor a phosphorylated at Ser216 confers inflammatory function to mouse microglia
}

Sawako Shindo ${ }^{1,2}$, Shih-Heng Chen ${ }^{3}$, Saki Gotoh ${ }^{1}$, Kosuke Yokobori ${ }^{1}$, Hao Hu', Manas Ray ${ }^{4}$, Rick Moore ${ }^{1}$, Kiyoshi Nagata ${ }^{2}$, Jennifer Martinez ${ }^{5}$, Jau-Shyong Hong ${ }^{3}$ and Masahiko Negishi ${ }^{1 *}$

\begin{abstract}
Background: Estrogen receptor a $(E R a)$ has been suggested to regulate anti-inflammatory signaling in brain microglia, the only resident immune cells in the brain. ERa conserves the phosphorylation motif at Ser216 within the DNA binding domain. Previously, Ser216 was found to be phosphorylated in neutrophils infiltrating into the mouse uterus and to enable ERa to regulate migration. Given the implication of this phosphorylation in immune regulation, ERa was examined in mouse microglia to determine if Ser216 is phosphorylated and regulates microglia's inflammation. It was found that Ser216 was constitutively phosphorylated in microglia and demonstrated that in the absence of phosphorylated ERa in ERa KI brains microglia inflamed, confirming that phosphorylation confers ERa with anti-inflammatory capability. ERa KI mice were obese and weakened motor ability.
\end{abstract}

Methods: Mixed glia cells were prepared from brains of 2-days-old neonates and cultured to mature and isolate microglia. An antibody against an anti-phospho-S216 peptide of ERa (aP-S216) was used to detect phosphorylated ERa in double immunofluorescence staining with ERa antibodies and a microglia maker Iba-1 antibody. A knock-in (KI) mouse line bearing the phosphorylation-blocked ERa S216A mutation (ERa KI) was generated to examine inflammation-regulating functions of phosphorylated ERa in microglia. RT-PCR, antibody array, ELISA and FACS assays were employed to measure expressions of pro- or anti-inflammatory cytokines at their mRNA and protein levels. Rotarod tests were performed to examine motor connection ability.

Results: Double immune staining of mixed glia cells showed that ERa is phosphorylated at Ser216 in microglia, but not astrocytes. Immunohistochemistry with an anti-lba-1 antibody showed that microglia cells were swollen and shortened branches in the substantial nigra (SN) of ERa KI brains, indicating the spontaneous activation of microglia as observed with those of lipopolysaccharide (LPS)-treated ERa WT brains. Pro-inflammatory cytokines were up-regulated in the brain of ERa KI brains as well as cultured microglia, whereas anti-inflammatory cytokines were down-regulated. FACS analysis showed that the number of IL-6 producing and apoptotic microglia increased in those prepared from ERa KI brains. Times of ERa KI mice on rod were shortened in Rotarod tests.

(Continued on next page)

\footnotetext{
* Correspondence: negishi@niehs.nih.gov

${ }^{1}$ Pharmacogenetics, Reproductive and Developmental Biology Laboratory,

National Institute of Environmental Health Sciences, National Institutes of

Health, Research Triangle Park, North Carolina 27709, USA

Full list of author information is available at the end of the article
}

\section{$\triangle B M C$}

(c) The Author(s). 2020 Open Access This article is licensed under a Creative Commons Attribution 4.0 International License, which permits use, sharing, adaptation, distribution and reproduction in any medium or format, as long as you give appropriate credit to the original author(s) and the source, provide a link to the Creative Commons licence, and indicate if changes were made. The images or other third party material in this article are included in the article's Creative Commons licence, unless indicated otherwise in a credit line to the material. If material is not included in the article's Creative Commons licence and your intended use is not permitted by statutory regulation or exceeds the permitted use, you will need to obtain permission directly from the copyright holder. To view a copy of this licence, visit http://creativecommons.org/licenses/by/4.0/ The Creative Commons Public Domain Dedication waiver (http://creativecommons.org/publicdomain/zero/1.0/) applies to the data made available in this article, unless otherwise stated in a credit line to the data. 
(Continued from previous page)

Conclusions: Blocking of Ser216 phosphorylation aggravated microglia activation and inflammation of mouse brain, thus confirming that phosphorylated ERa exerts anti-inflammatory functions. ERa KI mice enable us to further investigate the mechanism by which phosphorylated ERa regulates brain immunity and inflammation and brain diseases.

Keywords: Nuclear receptor, Estrogen receptor, Brain, Microglia, Inflammation, Phosphorylation

\section{Background}

Estrogen and estrogen receptor $\alpha(E R \alpha)$ are known to regulate anti-inflammatory signaling in the brain [1] and are directly involving in the pathogenesis of neurodegeneration and other inflammation-related brain diseases [2]. Microglia are the resident macrophages in the brain, responsible for the control of neuroinflammation [3]. Since ER $\alpha$ is ubiquitously expressed in the brain, the signaling that specifically regulates ER $\alpha$ in microglia remains uninvestigated. Moreover, a proper animal model that enables us to perform targeted examinations to microglia in brain does not currently exist. Here we have now found that ER $\alpha$ is phosphorylated at Ser216 in microglia and generated an ER $\alpha$ S216A knock-in $\left(E s r 1^{S 216 A}\right)$ mouse line to investigate whether this phosphorylation enables ER $\alpha$ to regulate inflammation of microglia. ERo's Ser216 (Ser212 in human ER $\alpha$ ) is present within the DNA binding domain (DBD) and conserved a phosphorylation motif in 41 out of 46 total mouse nuclear receptors (Additional file 1: Figure S1) as well as in the corresponding human nuclear receptors [4]. These extremely high crossspecies conservations strongly suggest critical regulatory functions this motif may plays for nuclear receptor actions. In fact, In addition to Ser216 of ER $\alpha$, the corresponding residues of four other nuclear receptors have been reported to be phosphorylated in mouse tissues in vivo and to confer specific function to them, which include Thr38, Ser100, Ser154 and Thr167 of constitute active/androstane receptor (CAR), retinoid-related orphan receptors $\alpha(\mathrm{ROR} \alpha)$, farnesoid X receptor (FXR) and retinoid X receptor $\alpha(\mathrm{RXR} \alpha)$, respectively [4-8]. For example, phosphorylation of Thr38 presses the constitutive activity of CAR, providing it with the response ability to its activator $[5,6]$. RXR $\alpha$ was found to be phosphorylated at Thr167 in mouse adipose tissues in response to fasting. We generated RXR $\alpha$ T167A knock-in mouse and demonstrated that this phosphorylation regulates blood glucose levels by altering energy metabolism in adipose tissues [8]. These observations confirmed that phosphorylation of this conserved motif can be a common regulatory factor of nuclear receptors. Thus, phosphorylation of Ser216 presents an experimental basis to examine $E R \alpha$ in this context. Post-translational modifications are known to be important for protein activities. We previously showed that human ER $\alpha$ S212 mutants regulated the different group of genes form those regulated when they were overexpressed in Huh-7 cells [9]. Moreover, it was revealed that serine 216 of ER $\alpha$ was phosphorylated in vivo in neutrophils infiltrating the mouse uterus using a specific phosphorylated ER $\alpha$ recognition antibody [10]. With respect to phosphorylation of ER $\alpha$, various residues were reported such as Ser118 and Ser167 in uterine fibroids or breast cancer cells [11, 12], although phosphorylation has not been observed with endogenous ER $\alpha$ in tissues in vivo. On the other hand, Ser216 enabled us to investigate the in vivo function of phosphorylated ER $\alpha$.

This manuscript analyzed inflammation of microglia of the ER $\alpha$ KI brain in comparison with that of ER $\alpha$ WT brains. Microglia in the brain and, subsequently, glia cells cultured from the brains of 2-day-old neonates were subjected to investigations by using immunohistochemistry, real-time PCR, ELISA, cytokine arrays, FACS and Western blots. With experimental observations obtained we will discuss the anti-inflammatory and anti-apoptotic functions of phosphorylated ER $\alpha$ in microglia. This ER $\alpha$ KI $\left(E s r 1^{S 216 A}\right)$ mouse is the first $\mathrm{KI}$ at a potential phosphorylation motif that shows a physiological phenotype and can be used as an animal model for the study of physiological functions of phosphorylated ER $\alpha$ and their molecular mechanism as well as for drug discovery and development targeting microglia.

\section{Results}

ERa phosphorylated at Ser216 in microglia

Mixed glia cells were isolated from brains of 2-day-old neonates and cultured for 2 weeks to mature microglia prior to immunofluorescence staining. For microglia, these glia cells were double stained with an anti-ER $\alpha$ or P-S216 peptide antibody (in green) with an anti-Iba-1 antibody (in red) (Fig. 1a). In microglia, both ER $\alpha$ antibodies stained the cytoplasm and nucleus, whereas a phosphorylated ER $\alpha$ antibody appeared to strongly stain the nucleus. Staining of ER $\alpha$ by an anti-P-S216 peptide antibody was further confirmed with enriched mature microglia from glia cultures (Fig. 1b). In these cells, no staining differences between two antibodies were observed. For astrocytes, glia cells were co-stained by an anti-ER $\alpha$ or P-S216 peptide antibody (in green) with an anti-GFAP antibody (in red) (Fig. 1c). Anti-ER $\alpha$ antibody strongly stained astrocytes, while the P-S216 peptide antibody barely stained these cells. Obtained observations indicate that ER $\alpha$ is phosphorylated at serine 216 in 


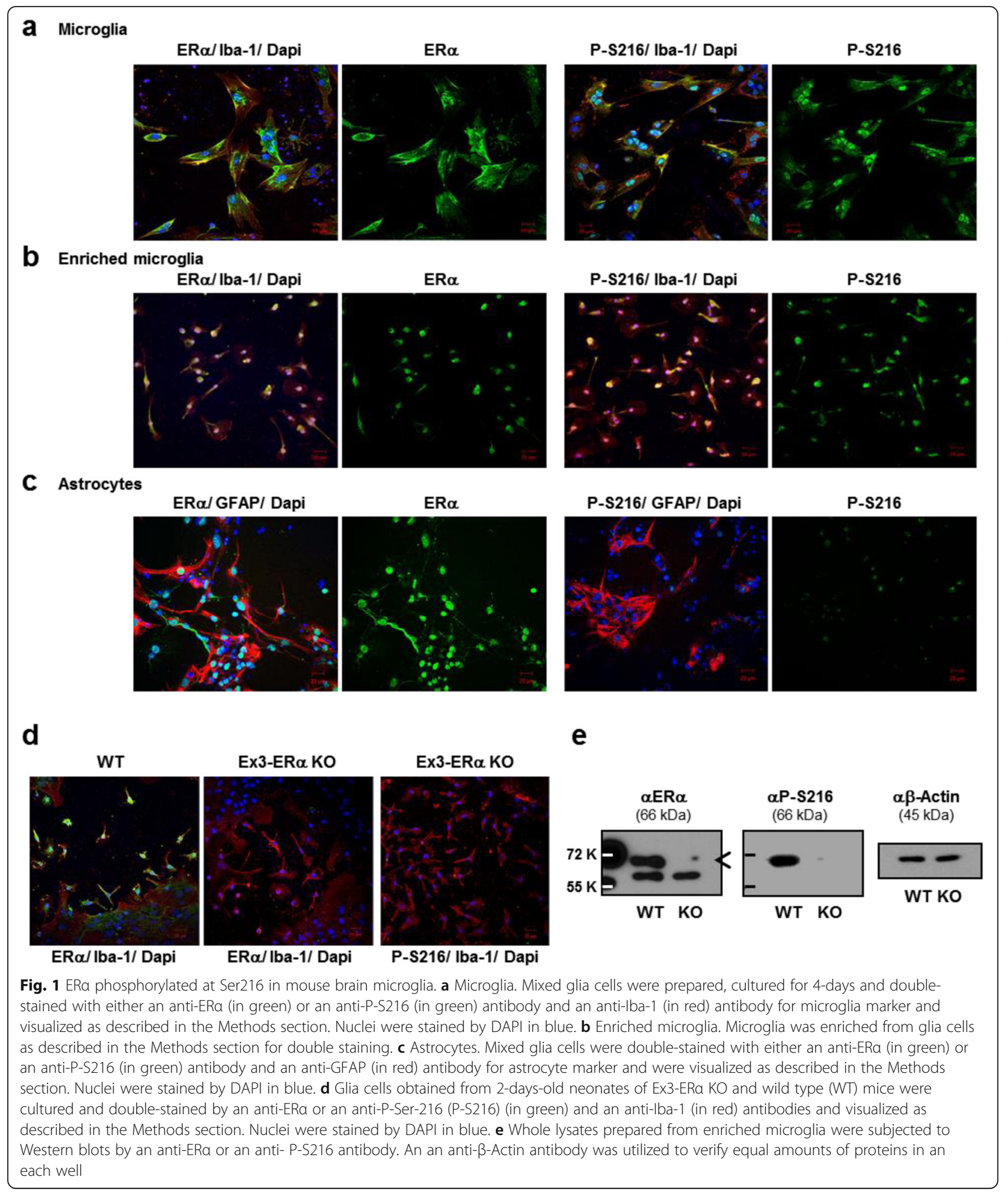

microglia and were expressed in the nucleus as well as in the extra-nuclear region. ER $\alpha \mathrm{KO}$ mice were further examined $E R \alpha$ in brain microglia. First, immunostaining was performed to show the absence of ER $\alpha$ in microglia
(Fig. 1d). Whole extracts from enriched microglia were subjected to Western blot analysis. Both an anti-ER $\alpha$ and P-S216 antibodies detected ER $\alpha$ band only in the extracts from ER $\alpha$ WT microglia (Fig. 1e). 
ERa S216A KI $\left(E s r 1^{S 216 A}\right)$ mice

Utilizing ACN cassette, a single mutation of serine 216 to alanine was introduced in the Esr1 gene (Fig. 2a). The mutation was verified by Southern hybridization (Fig. 2b) and PCR amplification (Fig. 2c). ER $\alpha$ mRNA and protein were equally expressed in the uterus of ER $\alpha$ WT and $\mathrm{ER} \alpha \mathrm{KI}$ mice (Fig. 2d and e) and the sequences of cDNAs confirmed the mutation (Fig. 2f). Moreover, coimmunostaining of glia cells with an anti-ER $\alpha$ and an anti-Iba-1 antibodies demonstrated the presence of ER $\alpha$ in microglia prepared from ER $\alpha \mathrm{KI}$ as observed as with $\mathrm{ER} \alpha$ WT mice (Fig. 2g). ER $\alpha$ KI mice were fertile; the pups were born normally in either ER $\alpha$ KI females or males. However, both male and female ER $\alpha$ KI mice developed obesity. At 6-month-old mice ER $\alpha$ KI mice were about $40 \%$ over-weight compared to WT mice (Fig. 2h).

\section{Microglia in adult ERa KI brains}

Although microglia are present throughout mouse brain, its distribution is much denser in specific regions such as olfactory telencephalon and substantia nigra (SN) reticulata [13]. Brain sections were prepared from saline- or LPS-treated adult ER $\alpha$ WT and KI males and stained with an anti-Iba-1 antibody (Fig. 3a). Intensities of Iba-1

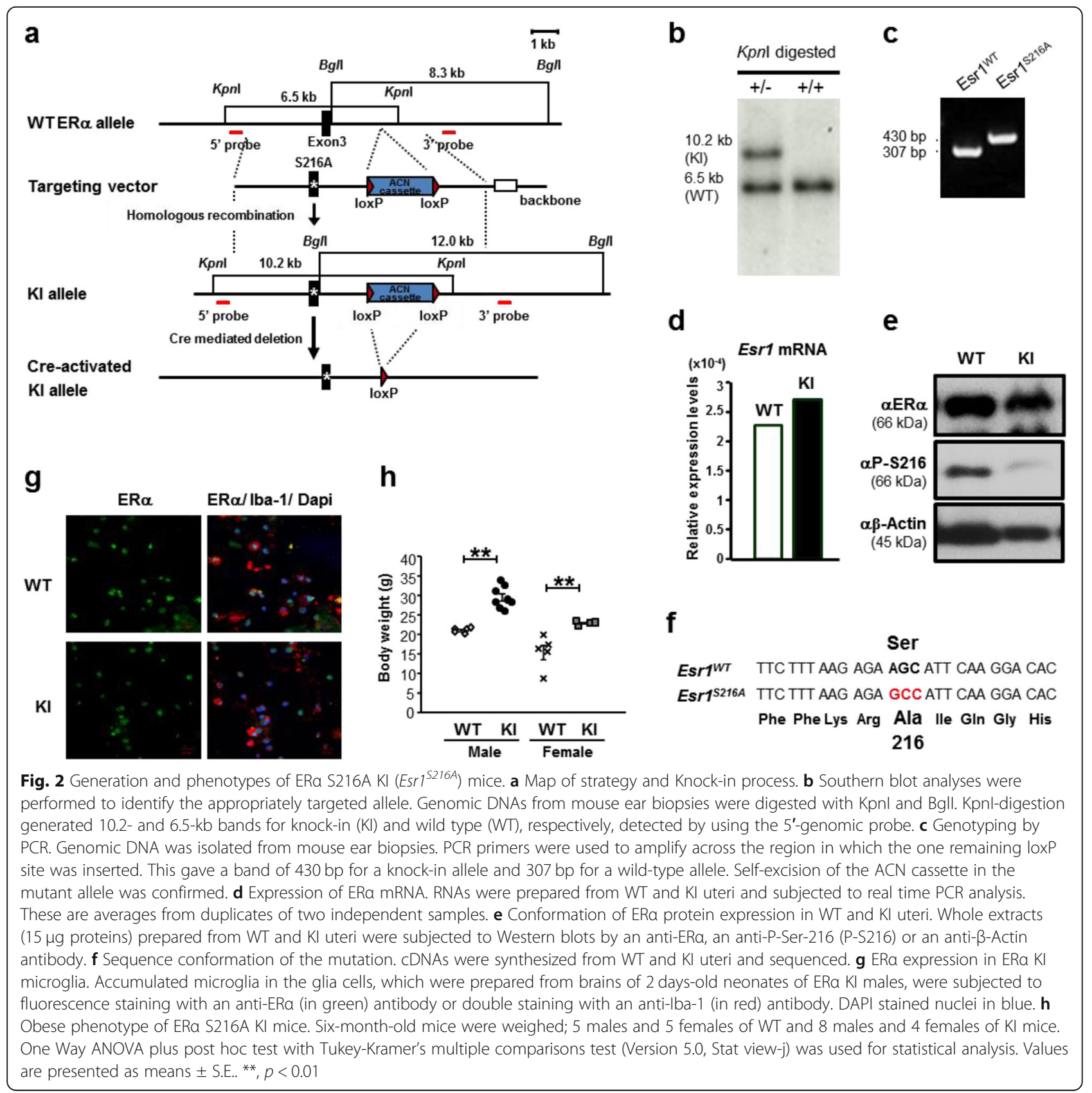




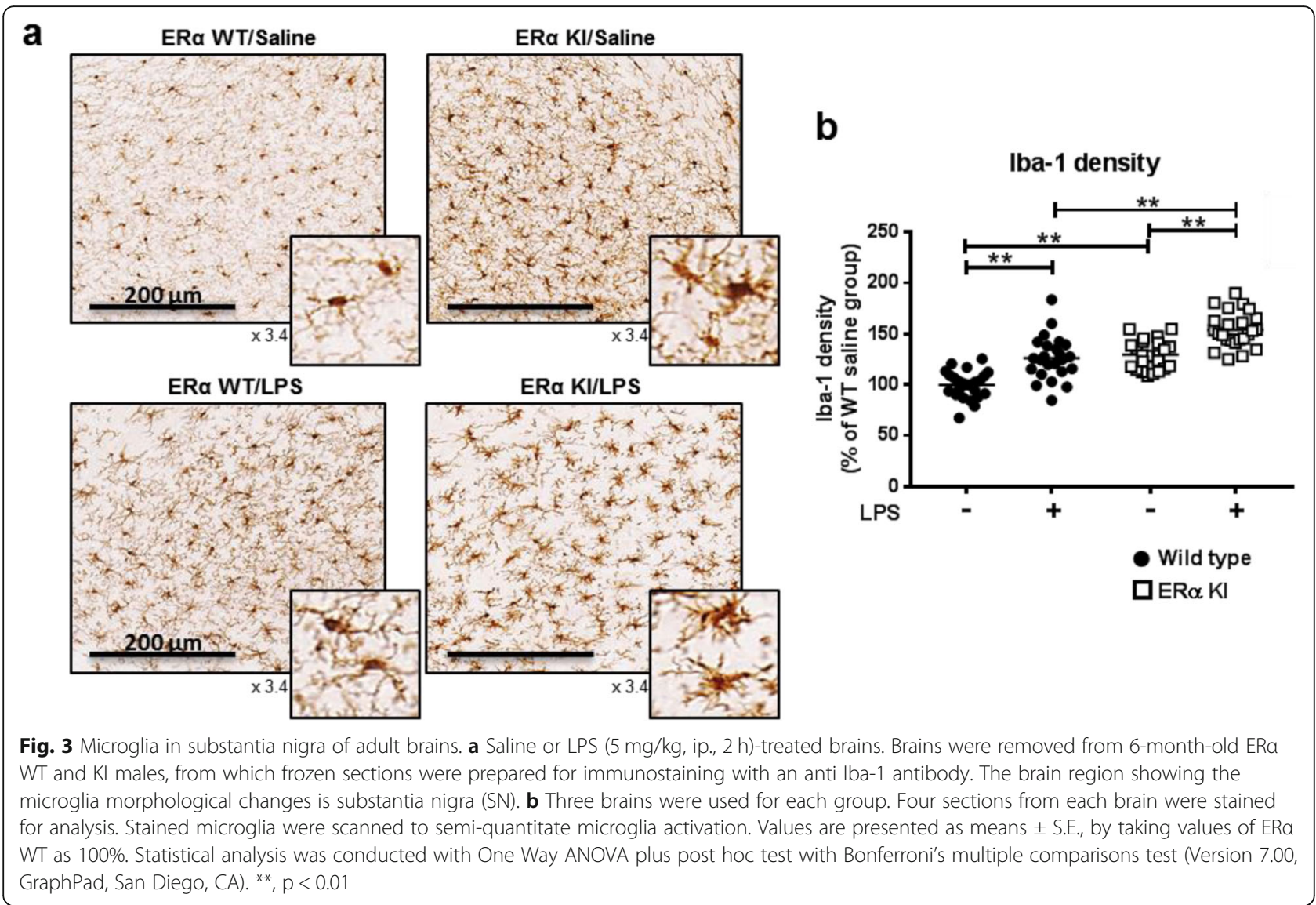

staining are known to increase as microglia become more activated [14]. Those intensities were higher in saline-treated ER $\alpha$ KI compared with those in ER $\alpha$ WT. Moreover, increases in the staining intensity by LPS treatment were $20 \%$ higher in ER $\alpha$ KI than in ER $\alpha$ WT mice (Fig. 3b). In addition, microglia developed morphological changes such as hypertrophic cells with pseudopodia in ER $\alpha$ KI mice (Fig. 3a). In the ER $\alpha$ WT /saline group, the microglia are small, spherical and rod-shaped cells, typifying morphology of resting microglia. On the other hand, in ER $\alpha \mathrm{KI} /$ saline brains, microglia are swelled, shortened and thickened, representing an active state, similar to those of ER $\alpha$ WT/LPS or ER $\alpha$ KI/LPS brains. These pictures represent a distinct state of microglia in ER $\alpha$ WT and KI mice. Microglial activation in response to various stimuli has been correlated with significant morphological changes [15]. Thus, blocking ER $\alpha$ phosphorylation at Ser216 aggravated microglia to increase both basal and LPS-induced activations. Brain extracts from adult ER $\alpha$ WT and KI mice treated with saline or LPS were subjected to RT-PCR analysis. LPSinduced mRNA levels of pro-inflammatory cytokines such as TNF- $\alpha$, IL- $1 \alpha$ and IL- $1 \beta$ were higher in ER $\alpha$ KI brains compared to ER $\alpha$ WT brains (Fig. 4a). Conversely, LPS-induced expression of an anti-inflammatory
IL-10 mRNA slightly diminished LPS in ER $\alpha$ KI brains. In addition, LPS induction of mRNAs for two enzymes, Cox-2 and iNOS, were higher in ER $\alpha$ KI brains; in particular, iNOS mRNA was induced only in KI brains. Subsequently, cytokine arrays were utilized to examine expressions of cytokines at their protein levels (Fig. 4b). Only a few cytokines were detected in the extracts of saline-treated brains and there was no difference in these expressions between $\mathrm{ER} \alpha \mathrm{WT}$ and KI brains. LPS treatment induced numerous cytokines and chemokines in both ER $\alpha$ WT and KI brains (Fig. 4c). Semi-quantitation of these expressions revealed that the degrees of these inductions were much higher in ER $\alpha$ KI than in WT brain (Fig. 4c). As observed with their mRNAs, protein levels of IL-6, IL- $1 \alpha$ and IL- $1 \beta$ also increased. However, no difference was observed in a TNF- $\alpha$ protein expression between WT and KI. In addition to cytokines, LPS-induced levels of chemokines and of a metalloprotease inhibitor TIMP-1 were higher in ER $\alpha$ KI than in WT brains. An integrin receptor ICAM-1 (also known as CD54) was also increased more in ER $\alpha$ KI brains after LPS treatment (Fig. 4b and c). These observations indicate that ER $\alpha$ KI microglia are more sensitive to LPS-elicited immune responses. 


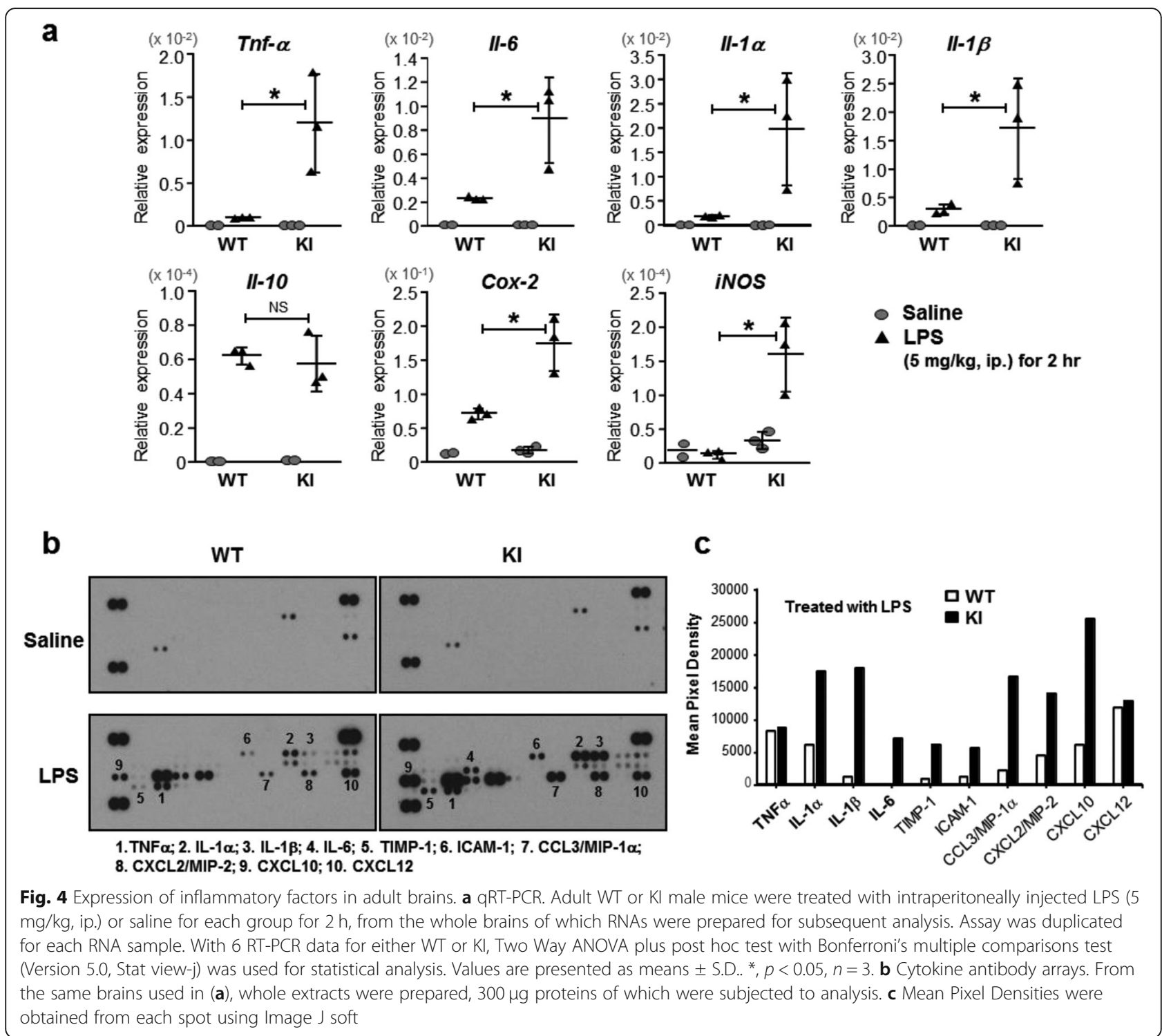

\section{Microglia in cultures}

Mixed glia cells were prepared from brains of 2-day-old neonates, cultured for 2 weeks so that microglia matured, and treated with LPS, from which supernatants were collected for ELISA (Fig. 5a). The increases of proinflammatory factors IL-6 and PGE2 were about 50\% higher in KI microglia after $24 \mathrm{~h}$ treatment. Conversely, an anti-inflammatory cytokine IL-10 was greatly repressed in KI microglia after $48 \mathrm{~h}$ treatment (Fig. 5a). Similar results were observed when examining intracellular levels of IL- 6 by fluorescence-activated cell sorting (FACS). Briefly, mixed glia cells prepared from 2-day-old neonates were treated with PBS or LPS for 2 or $24 \mathrm{~h}$. Male and female neonates were determined by different distances between anus and unitary opening. The mixed glial culture was the fixed and permeabilized to allow for antibody entry. Mixed glia cultures were stained for the microglia marker, $\mathrm{F} 4 / 80$, and $\mathrm{F} 4 / 80^{+}$microglia were analyzed for intracellular levels of IL-6. LPS-induced expression of IL-6 was approximately 35\% higher in ER $\alpha$ KI than in ER $\alpha$ WT microglia (Fig. 5b). FACS was also utilized to analyze apoptosis in mixed glia cultures. Annexin V binds extracellular phosphatidylserine, which is actively exposed during apoptosis. After LPS treatment, we also observed about $30 \%$ increase in apoptosis in ER $\alpha$ KI microglia, as determined by Annexin V positivity (Fig. 5c). Noticeably, there are no sex differences in the responses. Taken together, these results suggested that ER $\alpha$ KI microglia became increasingly inflammatory as well as apoptotic after LPS treatment.

\section{Motor connection ability}

Substantia nigra (SN) is an area of the brain that controls movement, microglia in which are associated with 
a
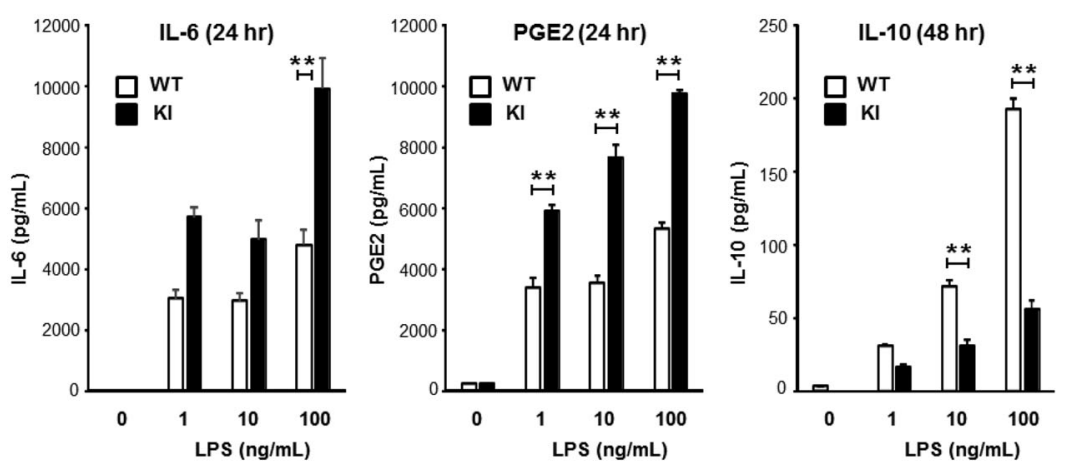

b
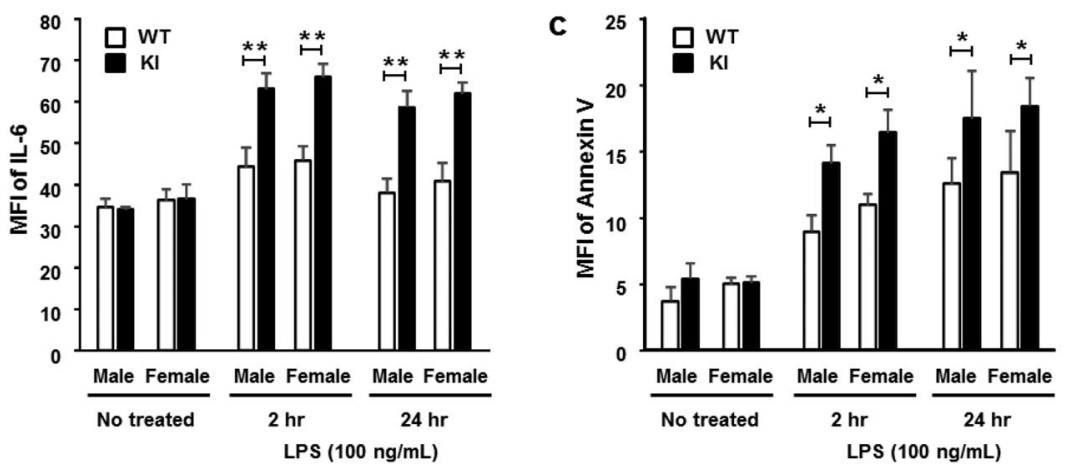

d

Representative FACS plots

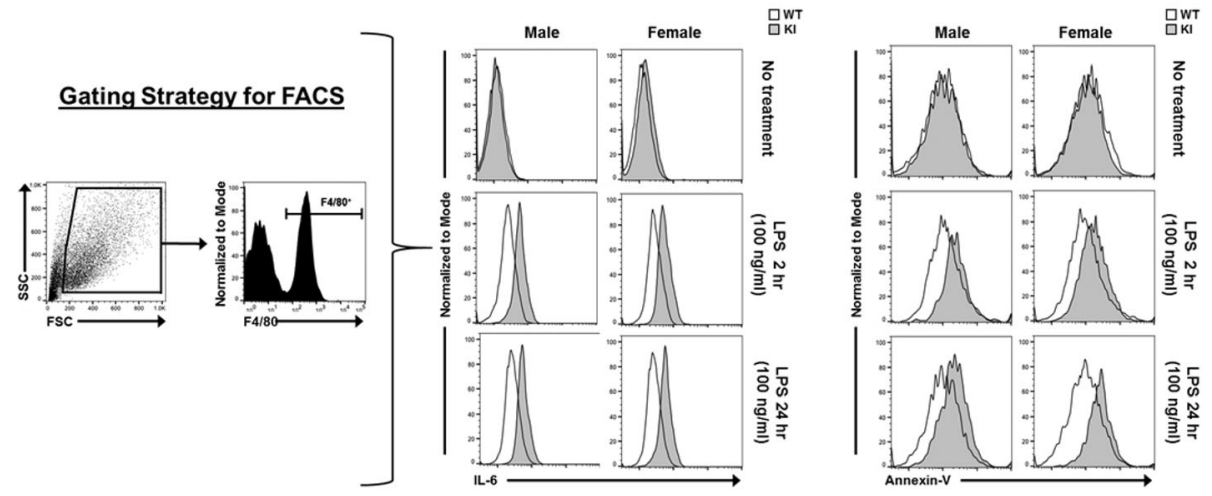

Fig. 5 Expression of inflammatory factors in cultured microglia. a ELISA. Mixed glia cells were prepared from 5 neonates and cultured for 2 weeks and then treated with 1,10 or $100 \mathrm{ng} / \mathrm{mL}$ of LPS or PBS for an additional 24 or $48 \mathrm{~h}$. Media were recovered and subjected to ELISA for IL-6, PGE2 and IL-10. WT and KI denote ERa wild type and KI mice, respectively. ONE Way ANOVA plus post hoc test with Tukey-Kramer's multiple comparisons test (Version 5.0, Stat view-j) was used for statistical analysis. Values are presented as means \pm S.D.. **, $p<0.01, n=4$. b FACS. Mixed glia cells were separately prepared from male and female neonates, cultured for 2 weeks and then treated with $100 \mathrm{ng} / \mathrm{mL}$ of LPS or PBS for an additional 2 or $24 \mathrm{~h}$. IL-6 production was determined by intracellular staining, followed by flow cytometry analysis. Assay was triplicated with three independent. ONE Way ANOVA plus post hoc test with Tukey-Kramer's multiple comparisons test (Version 5.0, Stat view-j) was used for statistical analysis. Values are presented as means \pm S.D. ${ }^{* *}, p<0.01$. c Cell death was assessed by Annexin $\vee$ staining, following by flow cytometry analysis. Assay was performed in triplicate eight times with three independent samples. These were separately prepared from male and female neonates. Two Way ANOVA plus post hoc test with Tukey-Kramer's multiple comparisons test (GraphPad Prism) was used for statistical analysis. Values are presented as means \pm S.D. ${ }^{*}, p<0.05$. $\mathbf{d}$ The gating strategy and the representative FACS plots for $b$ and $c$

this function. Given the finding that inflammation was aggravated in microglia of ER $\alpha$ KI brains, Rotarod tests were employed to examine whether motor connection was affected. It was found that average latencies were $206 \pm 57 \mathrm{~s}$ with 3 -month old WT mice (Fig. 6). The corresponding KI mice significantly decreased this latency to $138 \pm 17 \mathrm{~s}$, impairing motor connection. These degrees of latency were continuously observed with 6month old WT mice, $217 \pm 59$ and $146 \pm 59$ with WT and KI mice, respectively (Fig. 6). Thus, the microglia 


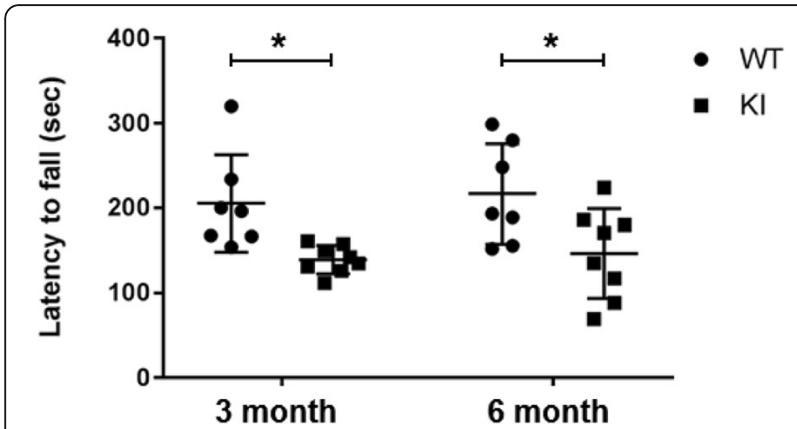

Fig. 6 Latency to fall in rotarod test. Three-month-old and 6-monthold male mice were tested as described in the Experimental Procedure section. These values are represented as mean \pm S.D. of 7-8 mice for each group. Data were analyzed by Two Way ANOVA plus post hoc test with Bonferroni's multiple comparisons test (version 7.02, GraphPad Prism) and are shown as scatter plots. $*, p<0.05$

expression of ER $\alpha$ S216A mutant appeared to deteriorate motor connection of mice.

\section{Discussion}

$E R \alpha$ is phosphorylated at Ser216 in microglia, only the immune cells in the brain. Microglia are the second immune cells which are found to express phosphorylated $E R \alpha$. Neutrophils infiltrating the mouse uterus were first found to express phosphorylated ER $\alpha$ [10]. Studies with ER $\alpha$ S216A KI (Esr1 $\left.1^{S 216 A}\right)$ mice show the antiinflammatory and anti-apoptotic functions of phosphorylated ER $\alpha$ in microglia. Microglia in substantial nigra are activated in the brain of ER $\alpha$ S216A KI mice. Inflammatory activation of these microglia has been associated with neurodegenerative diseases such as Parkinson [16, 17]. ER $\alpha$ S216A KI mice and microglia can be excellent experimental models for us to further implicate phosphorylated $\mathrm{ER} \alpha$ in inflammation-related neurodegenerative diseases and investigate their molecular and cellular mechanisms. ER $\alpha \mathrm{KO}$ females developed obesity and decreased glucose tolerance, suggesting that ER $\alpha$ plays a crucial role in estrogen-mediated metabolic regulation [18]. ER $\alpha$ S216A KI mice also showed an obesity phenotype and an increase boll glucose levels in both males and females, indicating that phosphorylation is critical for ER $\alpha$ to regulate these phenotypes. However, unlike the case of ER $\alpha \mathrm{KO}$ mice, this regulation may be both sex- and estrogen-independent.

Immunological study reported that M1/M2 polarization of macrophages plays an important role in controlling the balance between promotion and suppression in inflammation. Microglia protect brain cells from various stresses and insults by accelerating pro-inflammation to eliminate damaged cells (M1 microglia function) and, subsequently, decorrelating it to recover the brain form injury (M2 microglia function) [19]. Phosphorylated ER $\alpha$ is found to regulate both $\mathrm{M} 1$ and $\mathrm{M} 2$ functions, as indicated by the fact that an early expression of pro-inflammatory factors (e.g. IL-6 and PGE2) is stimulated and subsequent expression of anti-inflammatory factors (e.g. IL-10) is attenuated in LPS-treated ER $\alpha$ S216A KI mice. In other words, microglia in which ER $\alpha$ cannot be phosphorylated may have a strong function of $\mathrm{M} 1$ and may be less polarized to M2. Apoptosis is augmented in LPS-treated microglia from ER $\alpha$ S216A KI brains. In both the brain and cultured microglia, not all factors are regulated equally. However, phenotypes obtained by cultured microglia would reflect what should be observed in the brain. In addition, phosphorylated ER $\alpha$ may also have the potential to regulate microglia migration through the expression of cell adhesion molecules such as ICAM-1 and metalloprotease inhibitor TIMP-1. These patterns of regulations implicate phosphorylated ER $\alpha$ in the immune severance regulation to protect brains cells from injuries [20]. Rotarod tests found that ER $\alpha$ KI mice decreased motor ability. It remains to be seen if this correlate with decrease numbers of dopaminergic neurons in the areas of brain's substantia nigra. In addition to neurodegenerative diseases, recently, macrophage-elicited PGE2-EP2-NF- $\mathrm{kB}$ signaling in brains was linked to chronic inflammation, cerebral aneurisms and subarachnoid hemorrhage with NF-kB suggested to be a therapeutic target of aneurisms [21]. However, phosphorylated ER $\alpha$ may be a better target, possibly controlling inflammation but not the other signals in the brain.

The stimulated inflammation observed with ER $\alpha$ S216A KI brains closely resembles previous reports that microglia are activated by LPS in global ER $\alpha \mathrm{KO}$ mice [1], confirming the role of ER $\alpha$ in the inflammation. It was reported that estrogen repressed LPS-induced inflammation and apparently suppressed in isolated rat microglia from normal rat [22], suggesting the possibility that what this $E R \alpha$-mediated regulation was an estrogen action. However, our repeated experiments with cultured microglia did not find any effects of estrogen on their activities (unpublished). These differences between the two experiments are not reconciled now and whether estrogen directly regulates phosphorylated ER $\alpha$ in microglia remains further investigated in the future. Functions of ER $\alpha$ are primarily understood by estrogen actions with a gender-dependent manner predominately observed in females [23-25]. An alternative is the possibility that estrogen indirectly regulates phosphorylated ER $\alpha$ through astrocytes. A cross-talk between astrocytes and microglia is well known to regulate inflammation in the brain [26, 27]. Moreover, a recent report find that microglia play the determining role in sexual differentiation of the brain and estrogen may regulate microglia through astrocytes $[2,28]$. ER $\alpha$ is not phosphorylated in astrocytes (Fig. 1), possibly targeted by estrogen to transduce its signal to microglia. 
Microglia are critically involved in the development of various neurodegenerative diseases including Alzheimer's, Parkinson's and Huntington's diseases [16]. In fact, LPSinduced activation of microglia in the substantia nigra was associated with development of Parkinson disease [17, 29], although mice are known not to develop this disease [30]. Estrogen signaling has been investigated as a therapeutic target for developing drugs against neurotoxicity and injury as well as neurodegenerative diseases [26]. Phosphorylated ER $\alpha$ in microglia can be a more direct target of drug development. If chemicals that specifically bind and activate or inactivate phosphorylated ER $\alpha$ are identified, they may be effective in microglia but not the other cells in which ER $\alpha$ is not phosphorylated. Our previous study showed that human ER $\alpha$ S212D mutant activated EREreporter gene as observed with ER $\alpha$ WT and ER $\alpha$ S212A in Huh-7 cells [9], suggesting that cell-based reporter assays can be utilized to develop a high-throughput assay for identifying ligands specific to phosphorylated ER $\alpha$, with cells such as Huh-7 and/or mouse microglia-derived BV-2 cells. In addition to the brain, other tissues such as skin (Langerhans cells in) and liver (Kupffer cells) house resident macrophages. The presence of ER $\alpha$ was previously reported in these resident macrophages [31, 32], as well as bone marrow-derived and peritoneal macrophages [33]. ER $\alpha$ S216A KI mice can be utilized to examine if their inflammatory responses are altered. In fact, Kupffer cells isolated from ER $\alpha$ S216A KI mice expressed cytokines differently from those from normal mice (unpublished). Once confirmed, anti-inflammatory drugs that target skin and/or liver may also be developed.

\section{Conclusions}

ER $\alpha$ S216A KI mice are an excellent animal model for us to further investigate the inflammatory regulation of phosphorylated ER $\alpha$ and its molecular mechanism in microglia and implicate microglia in inflammation-related brain diseases. Current findings with this mouse provide experimental bases for us to further extend functional study of phosphorylated ER $\alpha$ into various directions which include generation of microglia-specific aberration of Ser216 phosphorylation. Once ER $\alpha$ is confirmed in human microglia, therapeutic drugs which selectively target phosphorylated ER $\alpha$ over non-phosphorylated ER $\alpha$. Together with our investigations using ER $\alpha$ S216A KI mice and RXR $\alpha$ T167A KI mice [8], we demonstrated the possibility that phosphorylation of the conserved motif within the DBD can be a common signal for nuclear receptors to diverge their functions.

\section{Methods}

\section{Materials}

An antibody against an anti-phospho-S216 peptide of ER $\alpha(\alpha \mathrm{P}-\mathrm{S} 216)$ was produced and evaluated by AnaSpec
Inc. (San Jose, CA). Iba-1 antibody and Antibody Diluent were purchased from WAKO; biotinylated goat antirabbit antibody and Vectastain $\mathrm{ABC}$ reagents from Vector Laboratory (Burlingame, CA); Mouse Cytokine Array Panel A and an anti-F4/80 antibody from R\&D Systems, Inc.; an antibody against green fluorescent protein (HRP-conjugated) from Abcam; an anti-Iba-1 antibody from Gene Tex; an Alexa 594 anti-Rat antibody and DMEM/F12 media from Life Technologies; Fixation/Permeabilization Solution Kit (BD Biosciences, San Jose, CA). Trizol from Life Technologies; Direct-zol ${ }^{\mathrm{Tm}}$ RNA kit from Zymo Research; RNeasy mini kit from Qiagen; MultiScribe Reverse Transcriptase from Applied Biosystems; an anti-GFAP antibody from STEMCELL Technologies; Precision Plus Protein Standards from Bio-Rad. All reagents are highest qualities commercially available.

Animals: Mice were maintained on a $12 \mathrm{~h}$ light $/ 12 \mathrm{~h}$ dark cycle and fed with NIH-31 the Open Formula Autoclavable diet (Zeigler, PA) and water ad libitum. Ex3-ER $\alpha$ KO mice were generous gift from Dr. Korach' lab. All research has been reviewed and approved by an Institutional Animal Care and Use Committee of NIEHS/NIH. LPS solution $(1 \mathrm{mg} / \mathrm{ml})$ was kept at $-20^{\circ} \mathrm{C}$ and thawed just before intraperitoneal injection. All experiments were performed in accordance with relevant guidelines and regulations.

\section{Generation ERa S216A KI (Esr1 $\left.{ }^{S 216 A}\right)$ mice}

A 5.1-kb left arm containing introns 2 and 3 and exon 3 and a $2.0-\mathrm{kb}$ right arm containing intron 3 were amplified from genomic DNAs of $\mathrm{C} 57 \mathrm{~B} / 6$ were cloned into pCR-XL-TOPO (Thermo Fisher Scientific, MA). Codon serine 216 encoded by exon 3 in the left arm was changed to alanine by site directed mutagenesis. After digestion with restriction enzymes, these DNA arms were cloned into the targeting vector which carries two multi cloning sites, self-excising ACN cassette [34] and DT-A cassette. The ACN cassette contains a testis-specific promoter from the angiotensin-converting enzyme gene that drives the expression of the Cre-recombinase gene, and RNA pol II promoter was used to drive neomycin registrant (neor) gene as a selection marker, which allows to screen ES cells in the presence of G418. When chimeras those are born from theses targeted ES-cells containing the ACN cassette are bred for germline transmission, somatic cells derived from the ES cells retained the cassette, but self-excision occurred in all ES-cellderived sperm, and as a result, the unexpected consequence due to the presence of Neo gene in chromosome can be avoided all together. The linearized targeting vector was electroporated into G4 embryonic stem cells (B6129F1 genetic background). The G418-resistant ES clones were screened by Southern blot analysis of KpnI- 
and BglI- digested genomic DNA with $5^{\prime}$ and $3^{\prime}$ external probes. BglI-digestion generated $12-$ and $8.3-\mathrm{kb}$ bands for KI and WT, respectively, detected by using the 3'-genomic probes. These Southern probes were amplified from ES cell genomic DNA: 5' probe, 130966/131442 (tgcagctgcttcctactggcttgaatcatccataaga tattaataagcaaacagtaaaaagatctgcggttggtaggggagttcaatactat gatgatgaaatggaaagtgatgggtaatagaataggaacaagaactggaagct ttgagccaatgctctctaaggatcactaaaaagtaaagaaatcctatctgaggct gccagcctcagagctaagttatttagagtggaaaaagttggccaactcagatgg actcaaaccaaggagccaatgttttgtgagttttatagccgatgtcatttacgaac cattaaaatattgtattcaatattaatgagggggaatagcagggaagggttatga aatacgagctgaaaggaaagctaggcctttgaggggaggaccagtgagttcat gtggctttgctatttgggacatggtgggactatgaagcagggaaccaggagctt cctta; 3' probe, 139971/140460 (ctgaagagatggctcagtggt taagagcatccactgtttgctcttccagaggattctggttcaattcccagctctca catagcagttaataactgtctgtaaactccagttcaagaggacctggcaccctca cacagacatacatgcaggcaaaacaccaatgcacataaaaataaatacatagt ttaagaacttcaggctcacttagcaggctctgtgtacttgtagagatctgtttcttt aatcttggggactcacctctgtccactcaagaggggctgtgctcacacttctttt caaattagttttctctctctgagtgcattcatgtgaagagtaggaggaatactaga agagccacccatttcttcacaggattattttatttctgagatctttttagagatatg tctgatcctatccactcccagcaaatagtaagtctttgttctcaacatttccactc atgaccctctctagtctgtaacag). Correctly targeted ES clones were microinjected into albino C57BL/6 J blastocyst and non-surgically transferred to pseudo-pregnant SWISS Webster females. Male germline chimeric founders were bred to wildtype C57BL/6 J females, which resulted in the removal of the self-excising positive selection marker. Self-excision of the positive selection cassette was confirmed by conventional PCR. Following removal of the positive selection marker, the line was crossed to C57BL/6 J wildtype mice one more generation, prior to in-crossing, and the resulting to obtain knock-in mice. Primers for genotyping by PCR used for $5^{\prime}$ probe $5^{\prime}$-TGCAGC TGCTTCCTACTGGCTTGA-3' and 5' ${ }^{\prime}$-TAAGGA AGCTCCTGGTTCCCTGCT-3'; for 3' probe, 5'CTGAAGAGATGGCTCAGTGGTTAA $-3^{\prime}$ and $5^{\prime}-$ CTGTTACAGACTAGAGAGGGT-3'.

\section{Primary cortical mixed glial culture}

Primary cortical mixed glial cultures were prepared from brains of mice at postnatal day $1-3$, as previously described $[35,36]$. Cortices were isolated from brains from which meninges and blood vessels were removed using forceps. Cells were dispersed by dissociating tissues in DMEM/F12 media through trituration. Obtained cell suspension were plated on either 24-well plates or 96well plates pre-coated in poly-D-lysine $(20 \mu \mathrm{g} / \mathrm{ml})$ at $1 \times$ $10^{5}$ cells/well or $5 \times 10^{4}$ cells/well. Cells were maintained in DMEM-F12 (1:1) media supplemented with 10\% heatinactivated fetal bovine serum, $2 \mathrm{mM} \mathrm{L}$-glutamine, $1 \mathrm{mM}$ sodium pyruvate, $100 \mu \mathrm{M}$ non-essential amino acids,
$50 \mathrm{U} / \mathrm{ml}$ penicillin, and $50 \mu \mathrm{g} / \mathrm{ml}$ streptomycin. Culture medium was changed every 3 days. To allow high yield of microglia in the culture, the cells were cultured for 2 weeks. The mixed glial cultures with a ratio of $20 \%$ microglia and $80 \%$ astrocytes were obtained [35].

\section{Microglia-enriched cultures}

Mouse microglia-enriched cultures were prepared from primary mixed glial cultures as previously described $(1,2)$. Mixed glia cultures were plated on $150 \mathrm{~cm}^{3}$ flasks precoated with poly-D-lysine $(20 \mu \mathrm{g} / \mathrm{ml})$ at $5 \times 10^{7}$ cells/flask and maintained in DMEM-F12 media changed every 3 days for 2 weeks. Then, matured microglia were shaken off at $180 \mathrm{rpm}$ for $40 \mathrm{~min}$ and re-plated on glass-bottom culture dishes (MatTek, Ashland, MA, USA) pre-coated with poly-D-lysine $(20 \mu \mathrm{g} / \mathrm{ml})$ at $1 \times 10^{6}$ cells/well.

\section{Immunohistochemical staining}

Mouse brain was first perfused with cold PBS to remove bloods, from which sections $(35 \mu \mathrm{m}$ thick) were prepared. Brain sections were treated with $1 \%$ hydrogen peroxide for $10 \mathrm{~min}$, incubated for $20 \mathrm{~min}$ with blocking solution (BSA 1\%/Triton X-100 0.4\%/Normal Goat Serum $4 \%$ in PBS) and incubated overnight at $4{ }^{\circ} \mathrm{C}$ with rabbit polyclonal antibody against Iba-1 (1:4000) in Antibody Diluent. Stained sections were washed in PBS three times each for $10 \mathrm{~min}$ and incubated for $2 \mathrm{~h}$ with PBS containing $0.3 \%$ Triton X-100 and a biotinylated goat anti-rabbit antibody (1:227). After washing three times with PBS, these sections were incubated for $1 \mathrm{~h}$ with the Vectastain $\mathrm{ABC}$ reagents diluted in PBS containing 0.3\% Triton X-100. Finally, these treated sections were incubated with 3, 3'-diaminobenzidine and urea-hydrogen peroxide tablets dissolved in water to visualize microglia. The nigral densities of the Iba-1 immunostaining were measured using ImageJ software. To quantify the Iba-1 staining of microglial cells in the substantia nigra, representative images of Iba-1-positive regions in the substantia nigra were captured at $40 \times$ magnification. A total of 100 microglia in each mouse were selected randomly, and the Iba-1 density was measured and normalize with size of area selected. One way ANOVA plus post hoc test with Bonferroni's multiple comparisons test was used to analyze the difference between saline injected WT microglia vs. LPS-injected WT or LPS-injected ER $\alpha$ KI.

\section{Elisa}

Cells were harvested and centrifuged to collected cultured media at time points after LPS (Millipore) treatment. Cytokine and metabolite concentrations were measured by ELISA. IL-6, IL-10 and PGE2 ELISA kits purchased from R\&D Systems. ELISA assays were performed according to the manufacturer's instructions. 
Cytokine antibody array: Mouse brains were homogenized in $500 \mu \mathrm{L}$ of cold PBS containing protease inhibitor cocktail and $5 \mu \mathrm{L}$ of Triton-X100 and centrifuged at $10,000 \times \mathrm{g}$ for $5 \mathrm{~min}$ at $4{ }^{\circ} \mathrm{C}$. Obtained lysates $(300 \mu \mathrm{g})$ were subjected to cytokine protein array. Cytokine expressions were detected by a mouse cytokine antibody array, panel A kit according to the manufacturer's instructions. Obtained spots were measured as densities by ImageJ software and showed in a graph. Cytokine mouse antibody array were performed according to the manufacturer's instructions.

\section{Double immunofluorescence staining}

Immunofluorescence staining was performed as previously described [37]. Mouse mixed glia or enriched microglia cells were cultured on $35 \mathrm{~mm}$ bottom glass dishes, fixed with $4 \%$ formaldehyde and blocked with a goat normal serum in PBS buffer for $20 \mathrm{~min}$. For the first staining, these dishes were incubated with given antibodies such as an anti-ER $\alpha$ and P-S216 antibody for 30 $\mathrm{min}$ at room temperature. For the second staining, stained dishes were washed with PBS buffer and incubated with marker antibodies such as anti-Iba-1 and GFAP antibodies for $30 \mathrm{~min}$ at room temperature. Subsequently, after washed with PBS, these dishes were incubated with a goat anti-rabbit IgG secondary antibody, Alexa Fluor 488 and a goat anti-mouse IgG secondary antibody, Alexa 594 (1:500) (Thermo Fisher) mixture at room temperature for $1 \mathrm{~h}$ in the dark. These stained cells were washed with PBS buffer and mounted with mounting medium containing DAPI (VECTASHIELD ${ }^{\circ}$ ). Stained cells in glass bottom dishes were observed using Zeiss 710 confocal microscopy (Zeiss).

\section{Flow Cytometry}

To assess cell death, mixed glia cultures were stained with an anti-F4/80 antibody (1:50) for $30 \mathrm{~min}$ on ice and Alexa 594 anti-rat antibody (1:500), followed by staining by Annexin- $\mathrm{V}$ as previously described [38], and acquisition on flow cytometer (LSRII, BD Bioscience). Annexin$\mathrm{V}$ positivity was analyzed for $\mathrm{F} 4 / 80^{+}$microglia singlets from mixed glia cultures using FlowJo software. To asses IL-6 expression, mixed glia cells were stained with an anti-F4/80 antibody (1:50) for $30 \mathrm{~min}$ on ice and Alexa 594 anti-rat antibody (1:500), followed by fixation/ permeabilization using Fixation/Permeabilization kit (BD PharmingenTM), washed in FACS buffer (PBS, 2\% BSA, $0.1 \mathrm{mM}$ EDTA, $0.1 \%$ sodium azide), collected by centrifugation and re-suspended in BD Perm/WashTM buffer. Then these cells were incubated with anti-PE-IL-6 antibody for $20 \mathrm{~min}$ on ice in dark. After washing, stained cells were suspended in $200 \mu \mathrm{L}$ of FACS buffer for immediate acquisition on flow cytometer (LSRII, BD Bioscience). The mean fluorescence intensity (MFI) for IL-6 in $\mathrm{F} 4 / 80^{+}$microglia singlets from mixed glia cultures was calculated using FlowJo software.

\section{Western blots}

Mouse uteri or brains were homogenized in $50 \mathrm{mM}$ Tris- $\mathrm{HCl}$ buffer saline ( $\mathrm{pH}$ 7.6) containing $8 \mathrm{M}$ urea and $1 \%$ SDS. After centrifugation, resulting supernatant was added to SDS sample buffer. Protein concentrations were determined by Bio-Rad protein assay (Bio-RAD, Hercules, CA). Proteins were separated on a SDS-PAGE and transferred onto PVDF membranes (GE Healthcare, Pittsburgh, PA). These membranes were blocked with $5 \%$ BSA or $5 \%$ skim milk in $50 \mathrm{mM}$ Tris-HCl-buffered saline containing $0.1 \%$ Tween-20 (TBS-T), incubated with given primary antibodies, washed with TBS-T, incubated with HRP-conjugated secondary antibodies and visualized using WesternBright Sirius HRP substrate (Advansta, Menlo Park, CA).

\section{RT-PCR}

Total RNAs were extracted from of enrich microglial cells using Trizol and a Direct-zolTM RNA kit. An RNeasy mini kit was used to extracts RNAs from mouse brains according to these manufacturer's instructions cDNAs were synthesized using MultiScribe Reverse Transcriptase. Real-time PCR was performed using an ABI prism 7700 sequence detection systems (Applied Biosystems) with following TaqMan probes (Applied Biosystems) used: human and mouse glyceraldehyde-3-phosphate dehydrogenase (Hs99999905_m1 and Mm99999915_g1) for an internal

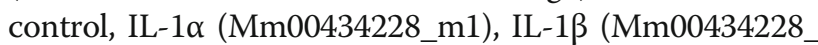
m1), IL-6 (Mm00446190_m1), IL-10 (Mm00439614_m1) and iNOS (Mm00440485-m1). Primers used for Cox-2 were primer-L: CAAGACAGATCATAAGCGAGGA and -R: GGCGCAGTTTATGTTGTCTGT. Assays were performed with a 7900HT Fast Real-Time PCR System (Applied Biosystems).

\section{Rotarod test}

Rotarod test was conducted by Rotamex-5 (Columbus instruments, Columbus, OH, USA). Groups of $7 \mathrm{ER} \alpha$ WT and of $8 \mathrm{ER} \alpha \mathrm{KI}$ males were trained for 4 consecutive days before they were tested at their 3-and 6-month of ages. Initial rotation of rotarod was set at $1 \mathrm{rpm}$ and incrementally accelerated $1 \mathrm{rpm}$ every $12 \mathrm{~s}$. Retention times (latencies) on rotarod to fall off from the rotarod was measured three times for each mouse and averaged.

\section{Statistical analysis}

Statistical analyses were conducted with One- or Two -Way ANOVA plus post hoc test with Bonferroni's multiple comparisons test or Tukey-Kramer's multiple comparisons test. Values are presented as means \pm S.E. or \pm S.D. 


\section{Supplementary information}

Supplementary information accompanies this paper at https://doi.org/10. 1186/s12964-020-00578-x.

Additional file 1: Figure S1. Amino acid sequence alignments of mouse nuclear receptors. Amino acid sequence alignments of mouse nuclear receptors to show the conserved phosphorylation site within the DNA binding domains.

\section{Abbreviations}

Cox-2: Cyclooxygenase-2; ELISA: Enzyme linked immunosorbent assay; ERa: Estrogen receptor a; FACS: Fluorescence-activated cell sorting; ICAM1: Intercellular adhesion molecule-1; MFI: Mean fluorescence intensity; IL: Interleukin; iNOS: inducible nitric oxide synthase; KI: Knock-in; KO: Knockout; LPS: Lipopolysaccharide; NF-KB: Nuclear factor-kappa B; PCR: Polymerase chain reaction; PGE2: Prostaglandin E2; RXRa: Retinoid X receptor a; TIMP-1: Tissue inhibitors of metalloproteinases-1; TNFa: Tumor necrosis factor $\mathrm{a}$; WT: Wild type

\section{Acknowledgments}

We would like to thank Drs. Sylvia Hewitt and Kenneth Korach for Ex3-ERa $\mathrm{KO}$ mice and Dr. Takeshi Hori for preparing an amino acid sequence alignment of mouse nuclear receptors. This work was supported by the fluorescence microscopy and imaging center, knockout mouse core laboratory and DNA sequence core laboratory of NIEHS.

\section{Authors' contributions}

All authors conceived and designed the experiments. SS and MN performed most of the experiments, analyzed and interpreted data and wrote the manuscript. SG and MR designed and produced Esr1 ${ }^{\text {S216A }}$ mouse. SS, S-HC, $\mathrm{KY}, \mathrm{HH}, \mathrm{RM}$ and $\mathrm{JM}$ performed the experiments and analyzed the data. All authors wrote or contributed to the writing of the manuscript. All authors read and approved the final manuscript.

\section{Funding}

This work was supported by the Intramural Research Program of the $\mathrm{NIH}$, National Institute of Environmental Health Sciences: Z01ES1005-01,

1 ZIAES10328601 and ZIA ES090082-20

\section{Availability of data and materials}

Not applicable.

\section{Ethics approval and consent to participate}

Not applicable.

\section{Consent for publication}

Not applicable.

\section{Competing interests}

The authors declare that they have no competing interests.

\section{Author details}

${ }^{1}$ Pharmacogenetics, Reproductive and Developmental Biology Laboratory, National Institute of Environmental Health Sciences, National Institutes of Health, Research Triangle Park, North Carolina 27709, USA. ${ }^{2}$ Departments of Environmental Health, Faculty of Pharmaceutical Sciences, Tohoku Medical and Pharmaceutical University, Sendai 981-8558, Japan. ${ }^{3}$ Neurobiology Laboratory, National Institute of Environmental Health Sciences, National Institutes of Health, Research Triangle Park, North Carolina 27709, USA. ${ }^{4}$ Knockout Mouse Core, National Institute of Environmental Health Sciences, National Institutes of Health, Research Triangle Park, North Carolina 27709. USA. ${ }^{5}$ Immunity, Inflammation and Disease Laboratory, National Institute of Environmental Health Sciences, National Institutes of Health, Research Triangle Park, North Carolina 27709, USA.
Received: 6 December 2019 Accepted: 13 April 2020

Published online: 29 July 2020

\section{References}

1. Vegeto E, Belcredito S, Etteri S, Ghisletti S, Brusadelli A, Meda C, Krust A, Dupont S, Ciana P, Chambon P, Adriana MA. Estrogen receptor-a mediates the brain antiinflammatory activity of estradiol. PNAS. 2003:100(16):9614-9.

2. Villa A, Vegeto E, Poletti A, Maggi A. Estrogens, Neuroinflammation, and Neurodegeneration. Endocr Rev. 2016;37(4):372-402.

3. Perdiguero TG, Geissmann F. The development and maintenance of resident macrophages. Nat Rev Immunol. 2016:17:1-9.

4. Hashiguchi T, Arakawa S, Takahashi S, Gonzalez FJ, Sueyoshi T, Negishi M. Phosphorylation of farnesoid $X$ receptor at serine 154 links ligand activation with degradation. Mol Endcrinol. 2016;30:1070-80.

5. Mutoh S, Osabe M, Inoue K, Moore R, Pedersen L, Perera L, Rebolloso $Y$, Sueyoshi T, Negishi M. Dephosphorylation of threonine 38 is required for nuclear translocation and activation of human xenobiotic receptor CAR (NR113). J Biol Chem. 2009;284:34785-92.

6. Mutoh S, Sobhany M, Moore R, Perera L, Pedersen L, Sueyoshi T, Negishi M. Phenobarbital indirectly activates the constitutive active androstane receptor (CAR) by inhibition of epidermal growth factor receptor signaling. Sci Signal. 2013:6:ra31.

7. Fashe M, Hashiguchi T, Yi M, Moore R, Negishi M. Phenobarbital-induced phosphorylation converts nuclear receptor RORa from a repressor to an activator of the estrogen sulfotransferase gene Sult1e1 in mouse livers. FEBS Lett. 2018:592(16):2760-8.

8. Sueyoshi T, Sakuma T, Shindo S, Fashe M, Kanayama T, Ray M, Moore R, Negishi M. A phosphorylation-deficient mutant of retinoid $X$ receptor $a$ at Thr167 alters fasting response and energy metabolism in mice. Lab Investig. 2019:99(10):1470-83

9. Shindo S, Sakuma T, Negishi M, Squires J. Phosphorylation of serine 212 confers novel activity to human estrogen receptor a. Steroids. 2012;77:448-53.

10. Shindo S, Moore R, Flake G, Negishi M. Serine 216 phosphorylation of estrogen receptor $a$ in neutrophils: migration and infiltration into the mouse uterus. PLoS One. 2013;8(12):e84462.

11. Murphy LC, Weitsman GE, Skliris GP, Teh EM, Li L, Peng B, Davie JR, Ung K, Niu YL, Troup S, Tomes L, Watson PH. Potential role of estrogen receptor alpha (ERalpha) phosphorylated at Serine118 in human breast cancer in vivo. J Steroid Biochem Mol Biol. 2006;102(1-5):139-46.

12. Hermon $T L$, Moore AB, Yu L, Kissling GE, Castora FJ, Dixon D. Estrogen receptor alpha (ERalpha) phospho-serine-118 is highly expressed in human uterine leiomyomas compared to matched myometrium. Virchows Arch. 2008;453(6):557-69.

13. Lawson LJ, Perry VH, Dri P, Gordon S. Heterogeneity in the distribution and morphology of microglia in the normal adult mouse brain. Neuroscience. 1990:39(1):151-70

14. Hoogland IC, Houbolt C, van Westerloo DJ, van Gool WA, van de Beek D. Systemic inflammation and microglial activation: systematic review of animal experiments. J Neuroinflammation. 2015;12:114.

15. von Bernhardi R, Heredia F, Salgado N, Muñoz P. Microglia function in the Normal brain. Adv Exp Med Biol. 2016;949:67-92.

16. Ataliah N, Vasiu R, Bosca AB, Cretu DI, Georgiu C, Constantin AM, Sovrea AS. Microglia-performers of the 21st century. Romanian J Morphol Embryol. 2014:55:745-65

17. Xueffi LQ, Wu X, Block ML, Liu Y, Breese GR, Hong JS, Kanpp DJ, Crews FT. Systemic LPS causes chronic neuroinflammation and protrusive neurodegeneration. Glia. 2007;55:453-69.

18. Heine PA, Taylor JA, Iwamoto GA, Lubahn DB, Cooke PS. Increased adipose tissue in male and female estrogen receptor-alpha knockout mice. Proc Natl Acad Sci U S A. 2000;97(23):12729-34.

19. Nakagawa Y, Chiba K. Role of microglial M1/M2 polarization in relapse and remission of psychiatric disorders and diseases. Pharmaceuticals. 2014;7: 1028-48.

20. Welser-Alves JV, Crocker SJ, Milner R. A dual role for microglia in promoting tissue inhibitor of metalloproteinase (TIMP) expression in glial cells in response to neuroinflammatory stimuli. J Neuroinflammation. 2011;8:61.

21. Aoki T, Frosen J, Fukuda M, Bando K, Shioi G, Tsuji K, Ollikainen E, Nozaki K, Laakkonen J, Narumiya S. Prostaglandin E2-EP2-NF-KB signaling in macrophages as a potential therapeutic target for intracranial aneurysms. Sci Signal. 2017;10:eaah6037. 
22. Bruce-Keller AJ, Keeling JL, Keller JN, Huang FF, Camondola S, Mattson MP. Antiinflammatory effects of estrogen on microglial activation. Endocrinology. 2000;141(10):3646-56.

23. Cunningham M, Gilkeson G. Estrogen receptors in immunity and autoimmunity. Clin Rev Allergy Immunol. 2011;40:66-73.

24. Baumgarten SC, Frasor J. Inflammation: an instigator of more aggressive estrogen receptor (ER) positive breast cancers. Mol Endocrinol. 2012;26:360-71.

25. Lang TJ. Estrogen as an immunomodulator. Clin Immunol. 2004;113:224-30.

26. Chen SH, Oyarzabal EA, Sung YF, Chu CH, Wang O, Chen SL, Lu RB, Hong $J S$. Microglia regulation of immunological and neuroprotective functions of astroglia. Glia. 2015;63:118-31.

27. Crider A, Pillai A. Estrogen signaling as a therapeutic target in neurodevelopmental disorders. J Pharmacol Exp Ther. 2017;360:48-58.

28. Villa A, Della Torre S, Maggi A. Sexual differentiation of microglia. Front Neuroendocrinol. 2019;52:156-64

29. Block ML, Zecca L, Hong JS. Microglia-mediated neurotoxicity: uncovering the molecular mechanisms. Nat Rev Neurosci. 2007;8:57-69.

30. Qin L, Wu X, Block ML, Liu Y, Breese GR, Hong JS, Knapp DJ, Crews FT. Systemic LPS causes chronic neuroinflammation and progressive neurodegeneration. Glia. 2007;55:453-62.

31. Vickers AE, Lucier GW. Estrogen receptor levels and occupancy in hepatic sinusoidal endothelin and Kupffer cells are enhanced in initiation with diethylnitrosoamine and promotion with 17a-enthinylestradiol in rats. Carcinogenesis. 1996;17:1225-42.

32. Mao A, Paharkova-Vatchkova V, Hardy J, Miller MM, Kovats S. Estrogen selectively promotes the differentiation of dendritic cells with characteristics of Langerhans cells. J Immunol. 2005;175:5146-51.

33. Kovats $\mathrm{S}$. Estrogen receptors regulate innate immune cells and signaling pathways. Cell Immunol. 2015;284:83-69.

34. Bunting M, Bernstein KE, Greer JM, Capecchi MR, Thomas KR. Targeting genes for self-excision in the germ line. Genes Dev. 1999;13:1524-8.

35. Chen SH, Oyarzabal EA, Hong JS. Preparation of rodent primary cultures for neuron-glia, mixed glia, enriched microglia, and reconstituted cultures with microglia. Methods Mol Biol. 2013;1041:231-40.

36. Liu B, Hong JS. Primary rat mesencephalic neuron-glia, neuron-enriched, microglia-enriched, and astroglia-enriched cultures. Methods Mol Med. 2003;79:387-95.

37. Shindo $S$, Moore R, Negishi M. Detection and functional analysis of estrogen receptor a phosphorylated at serine 216 in mouse neutrophils. Methods Mol Biol. 2016;1366:413-24.

38. Martinez J, Almendinger J, Oberst A, Ness R, Dillon CP, Fitzgerald P, Hengartner MO, Green DR. Microtubule-associated protein 1 light chain 3 alpha (LC3)-associated phagocytosis is required for the efficient clearance of dead cells. Proc Natl Acad Sci U S A. 2011;108:17396-401.

\section{Publisher's Note}

Springer Nature remains neutral with regard to jurisdictional claims in published maps and institutional affiliations.

Ready to submit your research? Choose BMC and benefit from:

- fast, convenient online submission

- thorough peer review by experienced researchers in your field

- rapid publication on acceptance

- support for research data, including large and complex data types

- gold Open Access which fosters wider collaboration and increased citations

- maximum visibility for your research: over $100 \mathrm{M}$ website views per year

At $\mathrm{BMC}$, research is always in progress.

Learn more biomedcentral.com/submissions 